\title{
Los polleros que engañan a los migrantes: norma o excepción
}

\author{
Smugglers who cheat migrants: rule or exception \\ Simón Pedro Izcara-Palacios / sizcara@uat.edu.mx \\ http://orcid.org/0000-0003-0523-305X \\ Universidad Autónoma de Tamaulipas, México
}

\begin{abstract}
This article, based on a qualitative methodology that includes in-depth interviews with 90 migrant smugglers, 20 procurers and 60 immigrants from Central America, examines the smugglers who cheat migrants. The results of this research indicate that many migrant smugglers only have the purpose to rob, kidnap or abandon migrants; that sex trafficking networks, which operate with some degree of deception, are growing; and that more and more migrant smugglers leave this industry, voluntarily or involuntarily, to join drug cartels. However, the main conclusion from the discourse of the interviewees is that there are more smugglers who lead migrants safe and sound to the United States than those who attack and do not care about them.
\end{abstract}

Key words: migrant smugglers, undocumented migration, prostitution, organized crime, Mexico, United States.

Resumen: Este artículo, fundamentado en una metodología cualitativa que incluye entrevistas en profundidad con 90 polleros, 20 proxenetas y 60 inmigrantes centroamericanos, examina a los polleros que engañan a los migrantes. Los resultados de esta investigación indican que muchos polleros sólo tienen la intención de robar, secuestrar o abandonar a los migrantes; que cada vez hay más redes de tráfico sexual, las cuales operan con cierto grado de engaño, y que cada vez son más los polleros que abandonan el coyotaje de forma voluntaria o involuntaria para formar parte de los cárteles de la droga. Sin embargo, la principal conclusión que se desprende del discurso de los entrevistados es que son más los polleros que conducen a los migrantes sanos y salvos a Estados Unidos que aquellos que los agreden y no los cuidan.

Palabras clave: polleros, migración indocumentada, prostitución, delincuencia organizada, México, Estados Unidos. 


\section{Introducción}

En la última década las políticas migratorias de México y Estados Unidos se han transformado en políticas de seguridad nacional, y el coyotaje ha sido equiparado a otras amenazas: el tráfico de drogas y armas, y el terrorismo. La equiparación de la migración indocumentada al narcotráfico y al terrorismo ha ido asociada a un cambio en la percepción del coyotaje. El argumento esgrimido por el discurso oficial es el siguiente: en el pasado el coyotaje era una actividad pacífica conducida por personas que formaban parte de la corriente migratoria; como contraste, en la actualidad la delincuencia organizada ha acaparado este negocio, que constituye una amenaza tanto para los migrantes como para la seguridad nacional (los polleros abusan de los migrantes, les roban, secuestran y abandonan, y las mismas redes que transportan migrantes mueven armas, drogas o terroristas).

El objetivo de este artículo es identificar a los polleros ${ }^{1}$ que engañan a los migrantes, buscan su lucro personal, y les roban o abandonan, y examinar si éstos son una excepción o constituyen la norma dentro de este negocio. La pregunta de investigación: ¿̇los polleros que engañan a los migrantes constituyen la norma o son una excepción? tiene una importancia mayúscula, ya que si éstos constituyen la norma, las férreas políticas de control fronterizo son adecuadas porque protegen las vidas de los migrantes y contienen las amenazas a la seguridad nacional; por el contrario, si éstos son una excepción, las costosas políticas de control fronterizo, desde los puntos de vista social y económico, no son justificables porque vulneran los derechos humanos de los migrantes. En el primer escenario, el Estado es una víctima y las muertes ocurridas en la frontera son únicamente imputables a la avaricia de las redes que lucran conduciendo migrantes. En el segundo escenario, el Estado es el victimario.

Este artículo examina a los polleros que engañan, roban, abandonan y explotan a los migrantes. En primer lugar, se describe la metodología utilizada, luego se analiza la figura de los polleros sin escrúpulos y se examinan a aquellos que roban y abandonan a los migrantes; finalmente se estudia a los polleros involucrados en redes de tráfico sexual y a aquellos implicados con los cárteles de la droga.

1 En este artículo utilizo de forma sinónima los términos: coyote, pollero y agente facilitador del cruce fronterizo. 


\section{Metodología}

Esta investigación se encuentra cimentada en una metodología cualitativa. La técnica que se utilizó para recopilar la información fue la entrevista en profundidad. Los entrevistados fueron visitados en dos ocasiones. En el primer encuentro, la duración fue superior a una hora; mientras la segunda visita tuvo una duración menor y abordó aquellos aspectos que quedaron inconclusos durante la primera visita. ${ }^{2}$ Las entrevistas fueron grabadas y transcritas. Por otra parte, el procedimiento para seleccionar a los entrevistados fue el muestreo en cadena.

El trabajo de campo fue realizado en diferentes localidades de Tamaulipas, Nuevo León, San Luis Potosí, México D.F., Estado de México y Chiapas. Entre los meses de abril de 2011 a mayo de 2013 fueron entrevistados 90 polleros. Los polleros tenían una edad promedio de 36.8 años, una media de 6.2 años de educación y se insertaron en el mercado laboral antes de cumplir diez años de edad. Los entrevistados comenzaron a trabajar como agentes facilitadores del cruce fronterizo entre los 16 y 41 años de edad, y en promedio sumaban 9.5 años de experiencia en el ejercicio de esta actividad (véase la Tabla $\left.1^{3}\right)$. El 23\% trabajaba única o principalmente para la comunidad migrante; mientras que el $77 \%$ proporcionaba migrantes a empleadores estadounidenses (véase la Tabla 2). Los entrevistados reclutaban inmigrantes tanto de México como de Centroamérica.

Entre los meses de junio de 2012 y mayo de 2013 fueron entrevistados 60 transmigrantes centroamericanos ( 32 hombres y 28 mujeres). Los varones tenían una edad media de 32.4 años y el promedio de edad de las mujeres alcanzaba los 30 años. Los primeros tenían únicamente 3.6 años de educación de media y las últimas 3.8 años, debido a que tuvieron que insertarse muy pronto en el mercado laboral para contribuir a la economía familiar. Los varones comenzaron a trabajar a una edad promedio de 8 años y las mujeres a la de 9.2 años. Todos los entrevistados habían sido deportados de Estados Unidos, habían quedado varados en México ${ }^{4}$ y tenían experiencia de haber emigrado a Estados Unidos con la ayuda de polleros. Las mujeres habían atravesado México guiadas por polleros una media de 2.2 veces y habían sido deportadas 1.3 veces; mientras que los varones contrataron a polleros 1.7 veces y fueron

2 En algunos casos no pudimos realizar un segundo encuentro con el entrevistado.

3 Todas las tablas se encuentran en el Anexo, al final del presente artículo (Nota del editor).

4 Los entrevistados habían quedado varados en México por alguna circunstancia (les robaron, no tenían suficiente dinero para pagar la tarifa cobrada por los polleros, los engañó el pollero, sufrieron un secuestro, etcétera). 
deportados una media de 1.4 veces (véase la Tabla 3). Por otra parte, como se aprecia en la Tabla 4, el 83\% de los entrevistados procedía de Guatemala, y el resto eran originarios de El Salvador, Honduras y Nicaragua. Los hombres habían encontrado empleo en diferentes actividades, mientras que todas las mujeres tenían experiencia de haber laborado en la industria de la prostitución.

Finalmente, entre los meses de septiembre de 2012 y febrero de 2013 fueron entrevistados 20 proxenetas mexicanos ( 15 mujeres y 5 hombres) que reclutaban mujeres para redes de tráfico sexual. El promedio de edad de los padrotes era de 42.2 años y el de las madrotas de 38.3 años. Los primeros tenían 7.6 años de educación y las últimas, 6.2 años. Los varones comenzaron a trabajar a una edad media de 10.6 años y las mujeres a la de 12.7 años; pero no se hicieron proxenetas sino hasta las edades promedio de 30.4 y 29.7 años, respectivamente. Mientras los primeros tenían 11.8 años de experiencia en esta actividad, las mujeres habían desempeñado ésta durante un promedio de 8.7 años (véase la Tabla 5).

\section{Los polleros sin escrúpulos: norma o excepción}

El discurso académico sobre el coyotaje se debate entre una posición hegemónica, que afirma que los polleros sin escrúpulos son la norma, y otra más marginal que considera a éstos como una excepción. Sin embargo, mientras la primera postura raramente recoge el discurso de los agentes facilitadores del cruce fronterizo, la segunda se sustenta en mayor medida en el relato de éstos.

El discurso que describe a los polleros como criminales sin escrúpulos justifica la férrea política de control fronterizo implementada por Estados Unidos en las áreas cercanas a los mayores núcleos poblacionales y de más fácil accesibilidad, ya que libera a las autoridades de toda responsabilidad por el incremento de muertes de migrantes ocurridas en la frontera. El discurso oficial pronto se apresuró en culpabilizar a los agentes facilitadores del cruce fronterizo por dichas muertes, quienes en su búsqueda del lucro personal desatienden las vidas de los migrantes: les roban, asaltan, violan y abandonan (HCHS, 2006: 18). Para Nevins (2003: 175), el intento de Washington por responsabilizar a los coyotes de dichas muertes sólo intenta ocultar al verdadero culpable: la infraestructura que hace más difícil cruzar por áreas urbanas.

El discurso académico recurrentemente ha achacado las muertes de migrantes a la avaricia de los polleros, quienes los abandonan en lugares desérticos donde sus probabilidades de supervivencia son escasas (Guerette y Clarke, 2005; García-Vásquez et al., 2007: 104; Addiechi, 2005: 174). Numerosos estudios indican que los polleros ya no inspiran confianza a los migrantes, 
porque han dejado de ser los personajes comunitarios de redes domésticas (Márquez-Covarrubias, 2015: 161; Martínez et al., 2015: 134; Slack et al., 2016: 22).

Incluso cuando se imputa la mortandad en la frontera a la política migratoria que busca explícitamente disuadir a los migrantes de cruzar la frontera, se describe a los polleros como miembros de organizaciones delictivas que victimizan a quienes contratan sus servicios (Feldmann y Durand, 2008: 23). Slack y Whiteford (2010: 89) reconocen que el discurso dominante que describe a los coyotes como criminales sin escrúpulos es sesgado; pero señalan que el robo, el tráfico de drogas y la esclavitud sexual son elementos que no pueden ser disociados del funcionamiento cotidiano del coyotaje. Es por ello que critican la postura de Spener (2009), quien al excluir de su análisis el robo, el narcotráfico y la esclavitud sexual, construye una imagen excesivamente positiva del coyotaje.

Este discurso distingue la situación actual, caracterizada por la presencia de redes de tráfico de personas operadas por la delincuencia organizada, que abusan y maltratan a los migrantes, de una situación pasada donde los polleros cuidaban a los migrantes. Sin embargo, a mediados del siglo pasado los coyotes no eran definidos en términos muy diferentes a los actuales.

Según Thompson (1956: 78), el endurecimiento de la Ley de Contratos Laborales de Foráneos de 1885 con la aprobación de la Ley migratoria de 1917 condujo a que muchos agricultores empleasen a coyotes, a quienes califica como gente sin escrúpulos que engañaban a los migrantes y los conducían al país vecino "apiñados en grandes grupos como si fuesen ganado".

Un grupo más reducido de académicos considera que los coyotes que explotan a los migrantes constituyen la excepción. Spener (2009: 155) define a las personas que engañan a los migrantes como falsos coyotes: individuos que fingen ser polleros. Para Spener (2011), coyotes y migrantes participan de una alianza estratégica de resistencia frente a la estructura represiva del apartheid global que se pone en práctica en las fronteras de los estados. Sharma (2003: 60) va más lejos y define a los agentes facilitadores del cruce fronterizo como las personas que más ayudan a los migrantes.

Otras investigaciones han constatado que la mayor parte de los polleros conducen a los migrantes sanos y salvos hasta el lugar de destino (Spener, 2004: 298; Kyle y Scarcelli, 2009: 306; Achilli, 2015: 6; Parks et al., 2009: 51 ), que la mayoría de los migrantes no reportan un trato abusivo (Kimball et al., 2007: 104; Fuentes y García, 2009: 89), que el coyotaje es un negocio separado del tráfico de drogas (Fuentes y García, 2009: 98; Spener, 2009: 156) y que ésta es una actividad no violenta realizada por personas ordinarias (Sánchez, 2016: 404). 
Todos los entrevistados reconocieron que algunos polleros engañaban a los migrantes. Jaime decía de modo categórico: "Hay polleros que no cuidan a las personas que llevan, o polleros que hasta venden a las personas que llevan, eso está comprobado". Sin embargo, ninguno de los entrevistados se incluyó en esta categoría; muy al contrario, algunos se definían como benefactores sociales.

Esto se refleja en expresiones como: "Me gusta ser pollero porque ayudo a la gente" (Gerardo) o "Yo siento que al ser pollero ayudo a las personas" (Guillermo). Ellos saben que la gente desconfía cada vez más de esta profesión; por eso muchos tratan de ganarse la amistad de sus clientes. Esteban decía: "Trato también que vean en mí a un compañero que los va a llevar, y a un amigo, trato de que se sientan seguros".

Algunos decían que lo más satisfactorio de la actividad que realizaban era ver cómo sus paisanos prosperaban económicamente. Como han señalado otros estudios (Achilli, 2015; Sánchez, 2016), casi todos definían su profesión como un trabajo decente y honrado. Manuel decía: "Es un trabajo donde no robo ni hago cosas malas; para mí es un trabajo decente y honrado". Asimismo, Zhang et al. (2007: 712) encontraron que los agentes facilitadores del cruce fronterizo chinos tenían una opinión positiva de la actividad que realizaban, y para muchos, ayudar a otros a alcanzar una vida mejor constituía un motivo de satisfacción.

Sánchez (2015) explica que los motivos económicos de los agentes facilitadores del cruce fronterizo en algunos casos son menos importantes que los motivos sociales, como ayudar a otros a migrar. Achilli (2015: 6) también encontró casos donde se priorizaba la ética sobre las ganancias.

Muchos de los entrevistados señalaban que lo más difícil de su profesión era cargar con la responsabilidad de transportar a los migrantes sanos y salvos hasta el lugar de destino. La militarización de la frontera ha incrementado los riesgos del coyotaje porque los territorios de más fácil accesibilidad a Estados Unidos, donde los migrantes corren menos peligros, están más vigilados. Por lo tanto, deben transitar por rutas más peligrosas (Parks et al., 2009: 36; Spener, 2009: 45).

En cada nuevo viaje se enfrentan a nuevos imprevistos: la mordedura de un animal, que alguien se quede rezagado o se deshidrate. Sortear cada vez mayores peligros es un reto. Ellos dicen que los migrantes son como niños a quienes tienen que cuidar. En terrenos tan peligrosos, la probabilidad de supervivencia de un adulto no es muy superior a la de un infante, todos dependen del buen hacer del pollero para llegar a Estados Unidos. Ellos dicen que la angustia de conducir a gente tan frágil e indefensa, que camina a ciegas 
por terrenos que esconden tantos peligros, les crea un nudo en el estómago, que no es producido por el miedo, sino por la carga de la responsabilidad.

Van bajo mi responsabilidad y tengo que cuidarlos, eso es lo que más me cuesta hacer, cuidarlos de los peligros que hay en el camino (Gregorio).

Aun sabiendo el camino, te preguntas: qué va a pasar; no sabes si te sale un animal o si alguien se te deshidrata o quizás se te caiga, no sabes cómo te va, y es una desesperación que se siente aquí adentro de ti, y no es miedo, es la carga de la responsabilidad (Juan).

Yo soy el responsable de ellos, porque van a lo desconocido, porque no conocen, y para mí son como niños, y no los puedo engañar (Marcos).

Los polleros son personas de profundas creencias religiosas. Ellos creen que Dios les protege, pero también piensan que es vengativo, y que cobrará su venganza si abusan de los migrantes. Cosme decía: "Dios me guía y me cuida mucho porque él ve que jamás he hecho algo malo que vaya en contra de lo que dice Dios; prefiero morir que hacer daño a las demás personas".

Asimismo, Benjamín afirmaba: "Tú respondes por ellos y tú los tienes que cuidar bien aunque sea a costa de tu vida”. Carmen relataba cómo en ocasiones tuvo que enfrentarse a las autoridades mexicanas, exponiéndose a que la detuvieran, para evitar que éstas abusaran de las mujeres que conducía. Igualmente, Horacio contaba que en una ocasión fue atrapado por las autoridades migratorias estadounidenses por salvar a un migrante que se estaba ahogando en el Río Bravo. Pero no son únicamente los polleros quienes se autodefinen como benefactores que arriesgan la vida por los migrantes; los últimos también lo afirman. Como señalaba Rufino:

En general los polleros son buenos, ellos andan arriesgando la vida por ayudarnos [...] Se arriesgan la vida por gente que a veces no conocen, como es el caso de nosotros los centroamericanos, que vamos de pasada por México [...] Lo que puedo decir es que los polleros son buenos y se ganan la vida pasando gente por México o pasando gente al norte; son buenos aunque las autoridades digan lo contrario y los traten mal, los polleros han ayudado a mucha gente.

\section{Los polleros que roban y abandonan a los migrantes}

Los migrantes que contratan a polleros para llegar a Estados Unidos corren el riesgo de que los últimos les roben sus pertenencias (Kimball et al., 2007: 97; Spener, 2009: 155), los abandonen (Cueva-Luna y Terrón-Caro, 2014: 234; Slack et al., 2016: 16; Martínez, 2016: 113) o los secuestren (Slack, 2016: 274; Slack y Campbell, 2016: 10). Los entrevistados conocían por experiencia que algunos polleros engañaban y abandonaban a los migrantes. Algunos polleros 
ayudaron a migrantes que abandonados por su guía habían quedado varados en el territorio fronterizo; otros relataban casos de migrantes que se quedaron sin dinero porque los engañaron, y otros conocían a polleros que llevaban a la gente con engaños para someterlos a un régimen de semiesclavitud.

He visto cómo los polleros abandonan a la gente en el camino (Enrique).

Hay polleros malos que no los cuidan o que los entregan a los delincuentes (Gerardo).

Allá me encontré a una persona que habían secuestrado, y le habían pedido rescate para liberarlo, y le dijeron que lo llevarían al otro lado, y no lo hicieron, sólo lo pasaron y lo abandonaron allá, y ahí nos lo encontramos en el camino (Humberto).

Hay polleros que abandonan a los que llevan y los dejan a ver cómo le hacen ellos y los dejan en el peligro, abandonados, y sin conocer a nadie (Ignacio).

Hay polleros que llevan a la gente con engaños y allá la dejan con un patrón que los pone a trabajar duro, y a veces no les pagan (Iván).

Los entrevistados achacan su mala fama a los coyotes que sólo persiguen el lucro personal, a quienes definen como falsos polleros. En este sentido, Spener (2009: 155) define como falso coyotaje a los individuos que ofrecen llevar a los migrantes a Estados Unidos; pero su única intención es asaltarlos.

Natalio decía: "Para mí que los que hacen mal a las personas no son polleros, pero se hacen pasar por polleros para engañarlos y quitarles el dinero". Algunos migrantes también piensan que los que los engañan no son verdaderos polleros. Susana afirmaba: "Conocí a un brasileño y un salvadoreño que andan por aquí, y ellos me dijeron que el pollero los había secuestrado; pero les dije ése no era pollero, era delincuente, por eso los engañó".

Los entrevistados subrayaban que el número de polleros que conducían a los migrantes sanos y salvos hasta su destino era superior al de aquellos que los abandonaban. Asimismo, Parks et al. (2009: 51) encontraron que todos los migrantes tlacotepenses que contrataron los servicios de polleros entraron exitosamente a Estados Unidos. Pero también decían que siempre habrá gente que tratará de engañarlos. Por lo tanto, quienes no investigan el historial del guía que van a contratar corren un riesgo. Como decía Francisco: "Hay polleros que engañan a la gente y la abandonan; pero no todos son iguales, aquí la gente que quiere ir siempre deben de buscar a gente que los oriente, que los recomiende, para mayor seguridad".

En la categoría de falsos polleros no aparecen incluidos únicamente aquellos que sólo tienen la intención de robar, secuestrar o abandonar a los migrantes, sino también los que carecen de experiencia. Cruzar la frontera es cada vez más complejo, está más vigilada que años atrás y hay nuevos peligros. 
Los polleros que quieren abrirse camino en esta profesión, pero carecen de experiencia, arriesgan la vida de los migrantes. Expresiones como: "Hay más polleros, pero no tienen experiencia" (Álvaro); "Hay polleros que no tienen mucho conocimiento" (Felipe); "Hay gente que no tiene experiencia y se anima a trabajar así, y ellos tienen miedo y no hacen bien las cosas" (Marcelo); "Hay nuevos que no tienen experiencia y por eso se les mueren ahogados o en el desierto, de calor" (Bartolomé); "Hay gente que no cuida a los que lleva y hasta se les llegan a morir porque no saben" (Bonifacio) o "Los polleros que llegan a ser malos y a engañar a las personas es porque son aprendices" (Miguel), se repiten de modo intermitente en las entrevistas.

Los migrantes centroamericanos siempre han desconfiado de los polleros; saben que los pueden engañar, por eso buscan referencias de éstos. Como decía Raimundo: "En aquel tiempo [1997] se sabía que los polleros abandonaban a las personas y las engañaban, decían que les quitaban el dinero, por eso yo busqué al pollero que me habían dicho".

En la actualidad, los peligros de la migración irregular son mayores (Slack, 2016; Izcara-Palacios, 2016). Esto ha incrementado la desconfianza hacia los polleros. Rodolfo decía: "Antes la gente era diferente, no desconfiaba de nadie, los polleros eran diferentes, y se tenía confianza”. Asimismo, Samanta dijo: "Antes era diferente la gente, no había maldad como ahora, los polleros eran comprometidos con la gente que llevaban, eran responsables y buenos".

El 16.7\% de los entrevistados fueron engañados en el último viaje por los polleros que contrataron (véase la Tabla 6). Otros estudios arrojan porcentajes similares. Kimball et al. (2007: 104) entrevistaron a 201 migrantes tunkaseños, y el 10.9\% fue violentado por asaltantes coludidos con los polleros. Por su parte, Fuentes y García (2009: 89) entrevistaron a 212 migrantes tlacuitapeños transportados a Estados Unidos por coyotes, y el 11.1\% reportó abusos. El engaño generalmente se produce de la siguiente manera: después de desembolsar el costo del viaje los polleros piden a los migrantes que los esperen en un restaurante o un hotel, pero huyen, dejándoles varados sin dinero en un país que desconocen.

Aquí nos dejó, descansamos en un hotel de paso, salió a comprar comida y no regresó, se fue con el dinero (Raúl).

Me cobró 2,100 dólares para pasarme, pero pues, no me pasó (Rodrigo).

Nos quedamos en un hotel de paso, agarramos dos cuartos, uno para los hombres y el otro cuarto para las mujeres [...] pero en la noche el pollero se fue con las mujeres y nos dejó dormidos (Rufo).

El pollero que nos traía me dijo que lo esperara, y lo esperé, pero no llegó (Sara). 
Los polleros que sólo tienen la intención de engañar a los migrantes suelen cobrar tarifas inferiores. Por lo tanto, los migrantes con menos recursos corren un mayor riesgo de ser engañados. Díaz-González (2009: 35) explica que ante un incremento del riesgo, los polleros honestos tienen que elevar sus tarifas, mientras que los deshonestos, que ex-ante no contemplan cumplir con el trato, no lo hacen; por lo tanto, los últimos acapararán una mayor cuota de mercado con el consiguiente perjuicio para los migrantes.

Sin embargo, los migrantes han aprendido a desconfiar de aquellos polleros que les ofrecen tarifas bajas. La mayoría espera durante semanas al pollero que les recomendaron o ahorran dinero durante meses para completar el pago de las tarifas ordinarias. Cada vez menos se apresuran a seguir a un pollero desconocido que les ofrece un trato demasiado atractivo. Parks et al. (2009: 53) también encontraron que los migrantes tlacotepenses desconfiaban de los coyotes fronterizos que cobraban menos.

Los migrantes centroamericanos en tránsito por México sufren elevados niveles de violencia tanto por la delincuencia organizada como por las autoridades mexicanas (Izcara-Palacios, 2016). Ante la gravedad de estas amenazas, la percepción del riesgo de ser violentados por los polleros aparece menguada.

Como refleja la Tabla 6 , frente a un $17 \%$ de los migrantes que fueron agredidos por los polleros, la mitad fueron violentados por la delincuencia organizada, y el $32 \%$ por las autoridades. Además, las agresiones de los grupos delictivos tienen consecuencias más severas que las de los polleros (Slack, 2016: 274).

Asimismo, Doezema (2010: 140) ha señalado que las autoridades constituyen una mayor amenaza que los traficantes. Es por ello que, como afirman Cueva-Luna y Terrón-Caro (2014: 231), a pesar del riesgo de contratar a un pollero, generalmente los migrantes tienden a confiar en ellos. Esto se refleja en expresiones como: "Siempre nos cuidó, fue bueno" (Omar); "Me ayudaron en lo que yo necesitaba, eran atentos" (Paolo); "Ellos les ayudan a las personas" (Pascual); "Fue buena persona, respetuoso" (Patricio); "Siempre fueron buenos, llevaban mujeres y fueron buenos con ellas" (Ramón); "Se portaron bien y nos cuidaron" (Ricardo); "Siempre nos ayudaron y no nos dejaron en el camino" (Roberto); "Son respetuosos y hacen su trabajo" (Socorro); "Son buenos, me trataron muy bien" (Sofía) o "Los polleros son buena onda" (Sonia).

Muchos relataban anécdotas de gente que había sido engañada; pero en la mayor parte de los casos su experiencia había sido positiva, por eso pensaban que había más polleros buenos que malos. Como decía Rodolfo: "Hay polleros que no son buenos, y no saben trabajar, pero opino que la mayoría 
son buenos polleros". Son las mujeres quienes presentan una mayor desconfianza hacia éstos. Eso se refleja en expresiones como: "Hay polleros buenos, pero hay malos y no sabes con quién te vas" (Samanta); "No puedes confiar, te trae el pollero pero vienes con miedo" (Sandra) o "No me engañaron como a muchos" (Sara).

Resulta llamativo que algunos migrantes centroamericanos no piensan que las elevadas tarifas que pagan sean excesivas. Rafael señalaba: "Pienso que son personas que ayudan a la gente, sí te cobran bien cobrado, pero es que ellos necesitan el dinero para ir pagando por el camino". Sabrina decía: "Los coyotes cobran bastante porque ellos también tienen que pagar para poder pasar". En este sentido, Aquino-Moreschi (2012: 14) estaba sorprendido por la imagen positiva que hay sobre los polleros entre muchos migrantes, quienes estaban agradecidos por los servicios recibidos aunque hubiesen pagado una cantidad elevada.

Lo más sorprendente es que algunos migrantes que fueron defraudados, no llegan a desconfiar totalmente de la persona que se quedó con su dinero. Rubio, un migrante guatemalteco que en septiembre de 2012 pagó $30 \mathrm{mil}$ pesos al pollero que lo conduciría de México DF a la frontera, decía: "Es la primera vez que el pollero me deja, no sé si nos dejó a propósito o salió y ya no pudo regresar por nosotros, sólo el pollero sabe qué le pasó, por qué nos dejó, se veía bueno".

Rufo, otro guatemalteco que en diciembre de 2012 pagó 25 mil pesos al pollero que lo conduciría desde Coatzacoalcos (Veracruz) hasta la frontera, señalaba: "El trato que me dieron fue bueno, lo que no entiendo es por qué este último pollero nos abandonó, y nos dejó sabiendo que no conocíamos este lugar".

\section{Coyotaje y explotación sexual}

Las redes que transportan mujeres para la industria de la prostitución han sido asociadas al engaño, la violencia y la esclavización (Agustín, 2007: 39; Hua, 2011: 44; Doezema, 2010: 138). Para Spener (2009: 159), el tráfico sexual no forma parte de las estrategias normales del coyotaje. Sin embargo, el tráfico sexual constituye una estrategia creciente en el negocio del coyotaje en la frontera mexicana-estadounidense. Muchos centros de entretenimiento adulto de Estados Unidos se nutren con la llegada de mujeres que fueron conducidas de modo irregular a través de la frontera.

Existen conexiones entre algunos centros de entretenimiento adulto estadounidenses y mexicanos. En algunos casos, estas conexiones son directas. 
Como decía Viola: "Los dueños de bares de Estados Unidos conocen a dueños de bares de México, así platican y se cambian a las mujeres para que trabajen más y haya más dinero". Pero en la mayor parte de los casos, las conexiones son indirectas. Los dueños de centros de entretenimiento adulto estadounidenses contratan a polleros mexicanos para que les lleven mujeres, y éstos generalmente las reclutan en bares, cantinas y casas de citas de México. Las mujeres demandadas en Estados Unidos son las más jóvenes y atractivas. Años más tarde, cuando pierden su atractivo, suelen regresar a México.

Las conexiones entre proxenetas mexicanos y polleros son estrechas. Expresiones como: "Yo, aparte de ser así (proxeneta), también ayudo a los polleros para la gente" (Yael); "Las podemos ayudar a que se vayan a Estados Unidos porque mi hijo es pollero" (Tania); "Hay polleros que vienen a buscar a las mujeres de aquî" (Vesta); "Hay un pollero que es mi amigo, él viene aquí, llega como si fuera su casa" (Vivencia) o "[el pollero] es mi camarada, mi cuate, ya lo conozco de años" (Vicenta), subrayan los lazos que unen a polleros y proxenetas.

Los primeros reclutan mujeres para los últimos; pero esto no suele realizarse mediante el engaño. Para los proxenetas entregar una de sus trabajadoras a un pollero implica una pérdida de ingresos, porque éstos sólo buscan a las más jóvenes y atractivas, que son las que generan más ingresos. Además, reciben poco dinero; los entrevistados hablan de cifras comprendidas entre quinientos y tres mil pesos por mujer.

Generalmente, los proxenetas ceden a los coyotes a aquellas mujeres que tienen una firme intención de trabajar en el país vecino. Los primeros obtienen un beneficio económico tanto si una de sus trabajadoras se va con un pollero como si se queda. Si la mujer va a Estados Unidos, el proxeneta recibe una comisión del pollero; si no va, recibe una parte de lo que ella gana. Talía, una mujer reclutada por un proxeneta en Chiapas, en 2004, cuando tenía 16 años de edad, para que trabajara en Estados Unidos, decía:

Ahí [en Chiapas] tenía un burdel, una cantina, ahí la tenía para enganchar a las mujeres y ofrecerles trabajo en Estados Unidos, las que aceptaban iban a trabajar al norte, y las que no, pues ahí seguían trabajando en la cantina, él [el proxeneta] como quiera no perdía nada, al contrario ganaba, ganaba dinero por las que conseguía y por las que se quedaban a trabajar como prostitutas.

Otro beneficio que obtienen los proxenetas de su relación con los polleros es la disposición periódica de nuevas mujeres. Los clientes se aburren pronto de las mujeres que trabajan en los establecimientos de entretenimiento adulto; por lo tanto, tienen más atractivo los lugares donde hay una mayor rotación de mujeres. Los polleros reclutan mujeres en estos centros, pero las que 
transportan también laboran temporalmente allí. Muchas veces estos establecimientos funcionan como casas de seguridad donde las mujeres descansan y trabajan. Aquellas que no tienen suficiente dinero para llegar a Estados Unidos suelen permanecer más tiempo en estos sitios; cuando ahorran para pagar la tarifa cobrada por el pollero, éste las recoge.

La coerción no constituye una forma habitual de reclutamiento utilizada por las redes de tráfico sexual. Numerosos estudios han constatado que muchas de las migrantes que laboran en la industria del sexo conocían de antemano la naturaleza del trabajo que realizarían en el país de inmigración (Agustín, 2007: 30; Doezema, 2010: 9; Lim, 2014: 14; Weitzer, 2015: 235). Todos los entrevistados dedicados al tráfico sexual, excepto uno, afirmaron que nunca engañaban a las mujeres (véase la Tabla 7). Expresiones como: "Desde aquí de México se les dice a ellas, y ellas vienen, y les digo cuál va a ser el trabajo" (Miguel); "Llevo a las que quieren ir [...] porque ya me conocen y me van recomendando unas con otras" (Narciso); "Siempre van las que quieren ir, yo no las llevo a la fuerza, ni las engaño, ni les miento" (Octavio) o "No se les lleva por la fuerza ni engañadas, es porque ellas quieren ir" (Oliverio), se repiten en casi todas las entrevistas.

Asimismo, los proxenetas entrevistados argumentaban que los coyotes no podían recurrir al engaño porque en Estados Unidos demandaban mujeres con experiencia y ganas de trabajar. El razonamiento es el siguiente: si las mujeres fuesen engañadas, éstas se negarían a trabajar, y los patrones estadounidenses no compensarían económicamente a los polleros mexicanos.

Los coyotes que conozco las llevan para allá [Estados Unidos] con experiencia, por eso no las pueden llevar engañadas porque les dicen a dónde van (Ysmael).

Van porque quieren ir, por eso se van y no las engañan, les dicen a qué van, no te conviene llevártelas engañadas porque luego no quieren trabajar y lo que se necesita es que trabajen para que le paguen al pollero por ellas (Zeferino).

Sin embargo, no todas las mujeres transportadas por redes de tráfico sexual conocen la naturaleza de la actividad que tendrán que realizar (Hua, 2011: 43). El 25\% de las migrantes centroamericanas entrevistadas fueron introducidas en la industria de la prostitución mediante engaños o a la fuerza (véase la Tabla 8). A algunas mujeres los polleros no les dicen que trabajarán en esta industria hasta que llegan a Estados Unidos, porque si les dijeran la verdad no querrían ir. Como decía Martín: "Hay mujeres que son penosas, y pues, a ellas se les ofrece el trabajo hasta que están allá en el otro lado [...] Estando allá se les dice que no hay trabajo en lo que les habíamos dicho".

Como afirmaba Tamara: "No me dijeron antes de irme, sino hasta que estaba allá, ya qué chingados hacía ya, estaba allá, lejos de mi familia, sin dinero, 
yo no imaginaba, ese trabajo eran hombres que por mucho tiempo no habían tenido mujer e iba yo a complacerles en el sexo, no me gustó la idea y quise regresarme, pero ya no me dejaron".

Asimismo, las mujeres transportadas voluntariamente por redes de tráfico sexual suelen desconocer las condiciones laborales y salariales que encontrarán en el país de destino. El 75\% de las mujeres entrevistadas sabía que trabajarían en la industria del comercio sexual y 79\% deseaban ser transportadas a Estados Unidos por redes de tráfico sexual (véase la Tabla 8), pero desconocían cuánto ganarían.

Zacarías, un proxeneta tamaulipeco que trabajó en un centro de entretenimiento adulto de Houston (Texas) entre 1984 y 1994 decía:

Ellas ya sabían a lo que iban, lo que no sabían era cuánto les iban a pagar, porque aquí [en México] les ofrecen un precio y estando allá [Estados Unidos] les pagan otro. Como quiera es buen dinero, pero ahí sí las engañaban con el pago. Te digo porque a veces me tocaba pagarles y ellas me decían: es que me dijeron que me iban a pagar más.

Vicenta también decía: "Nadie se las lleva a la fuerza, lo que les ha pasado es que les dicen que les van a pagar una cantidad de dinero y después no se las pagan, les pagan menos de lo que les ofrecieron; eso es lo que les ha pasado, como quien dice las engañan en la cantidad que van a ganar". Leandro señalaba: "Las ilegales dejan más dinero porque de cierto modo no saben mucho sobre sus derechos".

\section{Los polleros reclutados por los cárteles de la droga}

El crecimiento de la delincuencia organizada en México ha conducido a una complejización de las redes que conducen migrantes. Algunas redes simples se han fusionado para formar redes complejas, donde existe una mayor división del trabajo (Izcara-Palacios, 2014: 93). En estas redes, el líder supervisa la labor realizada por los numerosos polleros que forman parte de la misma, y negocia con los grupos delictivos el pago de un canon para que les dejen operar.

Recientes investigaciones señalan que los grupos criminales controlan a los polleros; de modo que los últimos ocuparían una posición jerárquica inferior dentro de una estructura liderada por el narcotráfico (MárquezCovarrubias, 2015: 161; Martínez et al., 2015: 134; Slack y Campbell, 2016: 16). Slack y Whiteford (2010: 90) afirman que "nuestras entrevistas con varios elementos de la policía municipal de Nogales, Sonora, nos hacen concluir que los que mandan a los coyotes se han aliado con los narcos". Sin embargo, esto no significa que "los que mandan a los coyotes" formen parte del crimen organizado. 
Juan, un pollero que trabajaba en una red que empleaba a dos decenas de coyotes, decía que su líder cambió la ruta donde operaban para evitar que los grupos delictivos invitaran o se llevasen a la fuerza a sus hombres. Si este líder (que introducía anualmente a varios miles de migrantes en Estados Unidos) formara parte de la delincuencia organizada no debería temer que sus polleros fuesen reclutados por los grupos delictivos.

Por eso hizo el patrón de cambiarnos de lugar donde trabajábamos, para que no nos fueran a invitar a que fuéramos con ellos [la delincuencia organizada], porque como dice el patrón: un hombre que me falte es uno y no lo repones fácilmente, es difícil encontrar quien quiera ser pollero, y más, quien sepa y que le guste.

Los polleros presentan un gran atractivo para los cárteles de la droga, pues conocen mejor que nadie los caminos y veredas del territorio fronterizo norteamericano por donde introducir drogas o traer armas (Izcara-Palacios, 2015: 331). Como decía Miguel: "Los polleros que se han llevado son para que les enseñen los caminos". Frecuentemente, los grupos delictivos los invitan a que dejen el coyotaje y trabajen para ellos. Como indican Slack y Campbell (2016: 13), es difícil discernir si los polleros que trabajan para la delincuencia organizada lo hacen voluntariamente o bajo coacción. Los más ambiciosos se dejan deslumbrar por un salario elevado.

Amadeo señalaba: "Hay unos cuantos que se han cambiado con ellos [la delincuencia organizada] porque les ofrecen pagarles más, y ellos, con ganas de tener más dinero se van con ellos y les ayudan a ellos; por lo regular lo que a ellos les mandan hacer es traficar la droga”. Aunque los jugosos salarios que les ofrecen inicialmente pronto menguan. Pero una vez que entraron a estos grupos ya no pueden salir, deben resignarse a unos ingresos cada vez más reducidos. Jorge comentaba el siguiente caso:

Conocí a uno que se fue porque le ofrecieron pagarle mejor, y más dinero, y dijo que le habían dicho que le van a pagar en dólares y decidió no seguir siendo pollero; pero no le pagaron lo que le dijeron, y cuando ya no quiso trabajar con ellos lo mataron y se lo mandaron descuartizado a su familia en una hielera.

Los polleros temen a los cárteles de la droga. Cuando son instados a formar parte de estas organizaciones generalmente declinan la invitación. Benito decía: "Sí me han insinuado algo, pero no trabajo para ellos, sólo les pago lo que me piden de dinero". Olga afirmaba: "Me habían invitado pero fui muy clara y les dije que no". Sin embargo, la mayor parte de los polleros no pueden evadir la invitación de unirse a los cárteles.

Como queda reflejado en las siguientes expresiones, muchas veces los delincuentes se acercan a los polleros con tono intimidatorio y se los llevan a la fuerza. 
[la delincuencia organizada] sí han contratado a algunos [polleros] y los ocupan, pero no es porque los polleros quieran trabajar con ellos, sino que los obligan a hacerlo (Emilio).

Los amenazan con matarlos a ellos o su familia, eso es lo que hacen, y ellos pues mejor prefieren trabajar con ellos antes que otra cosa pase (Esteban).

Yo conozco a varios que dicen: es que me amenazaron con matar a mi familia y por eso me fui a trabajar con ellos (Humberto).

La delincuencia organizada se ha llevado a polleros para que trabajen con ellos; pero se los llevan a la fuerza, no porque ellos quieran (Martín).

A muchos polleros han matado, otros han sido secuestrados y han sido llevados a trabajar con la delincuencia organizada (Miguel).

Se han ido a trabajar con ellos; pero no es por voluntad propia sino porque los obligan a hacerlo, se los llevan y ya no los traen (Narciso).

Aquellos que son amenazados suelen terminar accediendo al dictado de los delincuentes; pero también hay polleros que se rehúsan a colaborar con ellos. Como reflejan los siguientes ejemplos, algunos polleros prefieren perder la vida a colaborar con los delincuentes.

Un amigo que es de aquí de X., que llevaba gente, él me dijo que lo detuvieron a él, y ahí donde lo tenían había otro pollero y les dijeron a los dos por igual: ustedes quieren trabajar para nosotros o los matamos y les vamos a mandar su cabeza a los familiares, y dice mi amigo que el otro dijo: sí, yo sí trabajo para ustedes, jefe, yo no quiero morir, y él, mi amigo, dice que les respondió: yo prefiero morir que hacer cosas malas (Gerardo).

Les dije: no quiero pedos porque ya tengo muchos, y además, pues soy bien culo [cobarde], y si me han de querer llevar a la fuerza prefiero morir que hacer daño a las demás personas (Cosme).

\section{Conclusión}

Muchos polleros engañan a los migrantes, les roban y no los llevan hasta donde prometieron conducirles. Algunos de los entrevistados no pudieron cruzar la frontera, porque el pollero con quien realizaron el trato huyó con su dinero; pero esto no obedece al modo regular de operar de las redes que conducen migrantes.

El tráfico sexual constituye un área de crecimiento dentro del negocio del coyotaje. Las redes de tráfico sexual entrañan grandes riesgos porque operan con cierto grado de engaño. Los polleros sobredimensionan los salarios y no informan a las mujeres de las largas jornadas laborales ni de los escasos días de descanso. 
Sin embargo, los entrevistados decían que la mayor parte de las mujeres conducidas por estas redes conocían a qué las llevaban, deseaban ir a trabajar a los centros de entretenimiento adulto estadounidense y pagaban una elevada tarifa por ser conducidas allí. Esto era confirmado por la mayor parte de las mujeres centroamericanas entrevistadas; aunque una cuarta parte fueron conducidas con engaños o bajo coacción. Los resultados de esta investigación también indican que aquellas mujeres que trabajaron en esta industria y fueron deportadas pronto contactan con redes de tráfico sexual.

Por otra parte, cada vez más polleros terminan en las filas del crimen organizado. Algunos se dejan deslumbrar por el dinero fácil que les ofrecen los cárteles de la droga; pero si aceptan la invitación de los grupos delictivos corren un grave riesgo. Cuando reciben una invitación de los delincuentes intentan rehuirlos, aunque saben que darles una respuesta negativa puede tener un desenlace fatal. Por ello muchos de los polleros que se unen a estos grupos es bajo coacción. Además, los coyotes que se unen a la delincuencia organizada dejan de conducir migrantes a Estados Unidos.

En conclusión, los polleros que engañan, roban y abandonan a los migrantes constituyen más una excepción que la norma. La vulnerabilidad de los migrantes irregulares hace que los falsos polleros, algunas autoridades y la delincuencia organizada abusen de ellos. Los polleros que llevan años ejerciendo esta actividad generalmente les conducen hasta el lugar de destino. Los migrantes desconfían de los coyotes que les ofrecen tratos demasiado atractivos, y buscan a aquellos que les recomiendan parientes, amigos o paisanos. Estas son las estrategias que utilizan para distinguir a los malos de los buenos polleros; pero piensan que son más numerosos los últimos que los primeros. En contraste con el temor a ser detenidos por las autoridades o el pavor al azote de los grupos delictivos, los polleros son percibidos por los migrantes como una amenaza menor.

\section{Referencias}

Achilli, Luigi (2015), “The smuggler: Hero or felon?”, en Migration Policy Centre. Policy Briefs, núm. 2015/10, Italia: Migration Policy Centre.

Addiechi, Florencia (2005), Fronteras reales de la globalización. Estados Unidos ante la migración latinoamericana, México: UACM.

Agustín, Laura-María (2007), Sex at the margins. Migration, labour markets and the rescue industry, Estados Unidos: Zed Books.

Aquino-Moreschi, Alejandra (2012), "Cruzando la frontera: Experiencias desde los márgenes”, en Frontera Norte, vol. 24, núm. 47, México: Colegio de la Frontera Norte. 
Cueva-Luna, Teresa Elizabeth y Terrón-Caro, Teresa (2014), "Vulnerabilidad de las mujeres migrantes en el cruce clandestino por Tamaulipas-Texas”, en Papeles de Población, vol. 20, núm. 79, México: Universidad Autónoma del Estado de México.

Díaz-González, Eliseo (2009), "Riesgo moral y transmisión de señales: Análisis de la relación del pollero-mojado en una perspectiva microeconómica”, en Ra Ximhai, vol. 5, núm. 1, México: Universidad Autónoma Indígena de México.

Doezema, Jo (2010), Sex slaves and discourse masters. The construction of trafficking, Estados Unidos: Zed Books.

Feldmann, Andreas y Durand, Jorge (2008), “Mortandad en la frontera”, en Migración y Desarrollo, núm. 10, México: Red Internacional de Migración y Desarrollo.

Fuentes, Jezmín y García, Olivia (2009), "Coyotaje: The Structure and Functioning of the People-Smuggling Industry”, en Cornelius, Wayne A., Fitzgerald, David y Borger, Scott [eds.], Four generations of norteños. New Research from the Cradle of Mexican Migration, Estados Unidos: Centre for Comparative Immigration Studies.

García-Vázquez, Nancy et al. (2007), "Movimientos transfronterizos México-Estados Unidos: Los polleros como agentes de movilidad", en Confines de Relaciones Internacionales y Ciencia Política, vol. 3, núm. 5, México: Tecnológico de Monterrey.

Guerette, Rob y Clarke, Ronald (2005), "Border Enforcement, Organized Crime, and Deaths of Smuggled Migrants on the United States-Mexico Border”, en European Journal on Criminal Policy and Research, núm. 11, Estados Unidos: Springer International Publishing.

HCHS (House Committee on Homeland Security) (2006), A Line in the Sand: Confronting the Threat at the Southwest Border, Subcommittee on Investigations. Estados Unidos: House Committee on Homeland Security.

Hua, Julietta (2011), Tafficking women's human rights, Estados Unidos: University of Minnesota Press.

Izcara-Palacios, Simón (2014), "La contracción de las redes de contrabando de migrantes en México”, en Revista de Estudios Sociales, núm. 48, Colombia: Universidad de los Andes.

Izcara-Palacios, Simón (2015), "Coyotaje and drugs: Two different businesses", en Bulletin of Latin American Research, vol. 34, núm. 3, Inglaterra: Wiley.

Izcara-Palacios, Simón (2016), "Violencia postestructural: migrantes centroamericanos y cárteles de la droga en México", en Revista de Estudios Sociales, núm. 56, Colombia: Universidad de los Andes.

Kimball, Ann et al. (2007), "Impacts of US Immigration Policies on Migration Behavior", en Cornelius, Wayne A. et al. [eds.], Mayan Journeys: The New Migration from Yucatán to the United States, Estados Unidos: Center for Comparative Immigration Studies, University of California.

Kyle, David y Scarcelli, Marc (2009), "Migrant smuggling and the violence question: evolving illicit migration markets for Cuban and Haitian refugees", en Crime, Law and Social Change, vol. 52, núm. 3, Estados Unidos: Springer.

Lim, Timothy C. (2014), "Migrant Korean women in the US commercial sex industry: an examination of the causes and dynamics of cross-border sexual exploitation", en Journal of Research in Gender Studies, vol. 4, núm. 1, Estados Unidos: Addleton Academic Publishers.

Márquez-Covarrubias, Humberto (2015), "No vale nada la vida: éxodo y criminalización de migrantes centroamericanos en México", en Migración y desarrollo, vol. 13, núm. 25, México: Red Internacional de Migración y Desarrollo. 
Martínez, Daniel E. (2016), "Coyote use in an era of heightened border enforcement: New evidence from the Arizona-Sonora border”, en Journal of Ethnic and Migration Studies, vol. 42, núm. 1, Estados Unidos: Routledge Taylor \& Francis Group.

Martínez, Graciela et al. (2015), "Trazando rutas de la migración de tránsito irregular o no documentada por México”, en Perfiles latinoamericanos, vol. 23, núm. 45, México: FLACSO.

Nevins, Joseph (2003), “Thinking out of bounds: A critical analysis of academic and human rights writings on migrant deaths in the U.S.-Mexico border region", en Migraciones Internacionales, vol. 2, núm. 2, México: El Colegio de la Frontera Norte.

Parks, Kristen et al. (2009), "Strategies for success: Border crossing in an era of heightened security”, en Cornelius, Wayne A. et al. [eds.], Migration from the Mexican Mixteca. A transnational community in Oaxaca and California, Estados Unidos: Centre for Comparative Immigration Studies.

Sánchez, Gabriella (2015), "Human smuggling facilitators in the US Southwest", en Pickering, Sharon y Ham, Julie [comps.], The Routledge Handbook on Crime and International Migration, Estados Unidos: Routledge.

Sánchez, Gabriella (2016), "Women's Participation in the Facilitation of Human Smuggling: The Case of the US Southwest”, en Geopolitics, vol. 21, núm. 2, Estados Unidos: Routledge Taylor \& Francis Group.

Sharma, N. (2003), “Travel Agency: A Critique of Anti-Trafficking Campaigns”, en Refuge, vol. 21, núm. 3, Canadá: Centre for Refugee Studies at York University.

Slack, Jeremy y Whiteford, Scott (2010), "Viajes violentos: La transformación de la migración clandestina hacia Sonora y California”, en Norteamérica, vol. 5, núm. 2, México: UNAM.

Slack, Jeremy (2016), “Captive bodies: migrant kidnapping and deportation in Mexico”, en Area, vol. 48, núm. 3, Estados Unidos: Wiley.

Slack, Jeremy y Campbell, Howard (2016), "On Narco-coyotaje: Illicit Regimes and Their Impacts on the US-Mexico Border”, en Antipode, vol. 48, núm. 5, Estados Unidos: Wiley.

Slack, Jeremy et al. (2016), “The Geography of Border Militarization: Violence, Death and Health in Mexico and the United States", en Journal of Latin American Geography, vol. 15, núm. 1, Estados Unidos: Elsevier.

Spener, David (2004), "Mexican Migrant-Smuggling: A Cross-Border Cottage Industry”, en Journal of International Migration and Integration, vol. 5, núm. 3, Holanda: Springer Netherlands.

Spener, David (2009), Clandestine Crossings: Migrants and Coyotes on the Texas-Mexico Border, Estados Unidos: Cornwell University Press.

Spener, David (2011), "Global Apartheid, Coyotaje, and the Discourse of Clandestine Migration. Distinctions between Personal, Structural and Cultural Violence”, en Kyle, David y Kolowski, Rey, Global Human Smuggling. Comparative Perspectives, Estados Unidos: The Johns Hopkins Press.

Thompson, Albert (1956), “The Mexican Immigrant Worker in Southwestern Agriculture”, en American Journal of Economics and Sociology, vol. 16, núm. 1, Estados Unidos: Wiley.

Weitzer, Ronald (2015), "Human trafficking and contemporary slavery", en Annual Review of Sociology, vol. 41, Estados Unidos: JSTOR.

Zhang, Sheldon et al. (2007), "Women's participation in Chinese Transnational Human Smuggling: A gendered market perspective”, en Criminology, vol. 45, núm. 3, Estados Unidos: Wiley. 


\section{Anexo}

\section{Tabla 1}

\section{Características de los polleros entrevistados}

\begin{tabular}{lcccccc}
\hline & Media & Mediana & Moda & Mín. & Máx. & $\begin{array}{c}\text { Desviación } \\
\text { estándar }\end{array}$ \\
\hline Edad & 36.8 & 37 & 35 & 21 & 48 & 5.53 \\
\hline Años de educación & 6.2 & 6 & 6 & 0 & 12 & 2.81 \\
\hline $\begin{array}{l}\text { Edad cuando comenzó a } \\
\text { trabajar }\end{array}$ & 9.9 & 10 & 10 & 5 & 18 & 3.02 \\
\hline $\begin{array}{l}\text { Edad cuando empezó a } \\
\text { trabajar como pollero }\end{array}$ & 27 & 28 & 29 & 16 & 41 & 5.19 \\
\hline $\begin{array}{l}\text { Años de experiencia } \\
\text { como pollero }\end{array}$ & 9.5 & 9 & 10 & 4 & 21 & 4.05 \\
\hline
\end{tabular}

Fuente: Elaboración propia.

Tabla 2

\section{Caracterización de los polleros entrevistados}

\begin{tabular}{llll}
\hline \multirow{2}{*}{$\begin{array}{l}\text { Polleros que trabajan única o principalmente para la comunidad } \\
\text { migrante }\end{array}$} & 21 & 23.3 \\
\hline \multirow{3}{*}{$\begin{array}{l}\text { Polleros que trabajan única o principalmente para } \\
\text { los empleadores estadounidenses en diferentes }\end{array}$} & Agricultura & 43 & 47.8 \\
\cline { 2 - 4 } sectores económicos & Prostitución & 15 & 16.7 \\
\cline { 2 - 4 } & Construcción & 7 & 7.8 \\
\cline { 2 - 4 } & Servicios & 4 & 4.4 \\
\cline { 2 - 4 } & Total & 69 & 76.7 \\
\hline Total & & 90 & 100.0 \\
\hline
\end{tabular}

Fuente: Elaboración propia. 


\section{Tabla 3}

Características de los migrantes centroamericanos entrevistados

\begin{tabular}{|c|c|c|c|c|c|c|c|}
\hline & & Media & Mediana & Moda & Mín & Máx & $\begin{array}{l}\text { Desviación } \\
\text { estándar }\end{array}$ \\
\hline \multirow[t]{2}{*}{ Edad } & Varones & 32.4 & 33 & 36 & 20 & 40 & 4.75 \\
\hline & Mujeres & 30 & 30 & 32 & 24 & 41 & 4.43 \\
\hline \multirow{2}{*}{$\begin{array}{l}\text { Años de } \\
\text { educación }\end{array}$} & Varones & 3.6 & 3 & 0 & 0 & 9 & 3.7 \\
\hline & Mujeres & 3.8 & 5 & 6 & 0 & 9 & 2.82 \\
\hline \multirow{2}{*}{$\begin{array}{l}\text { Edad cuando } \\
\text { comenzó a } \\
\text { trabajar }\end{array}$} & Varones & 8 & 7 & 6 & 6 & $\mid 13$ & 2.37 \\
\hline & Mujeres & 9.2 & 9 & 6 & 6 & 15 & 2.82 \\
\hline \multirow{2}{*}{$\begin{array}{l}\text { Número de veces } \\
\text { que ha migrado } \\
\text { con la ayuda de } \\
\text { polleros }\end{array}$} & Varones & 1.7 & 1 & 1 & 1 & 3 & 0.83 \\
\hline & Mujeres & 2.2 & 2 & 2 & 2 & 4 & 0.52 \\
\hline \multirow{2}{*}{$\begin{array}{l}\text { Número de } \\
\text { veces que fueron } \\
\text { deportados de } \\
\text { Estados Unidos }\end{array}$} & Varones & 1.4 & 1 & 1 & 1 & 3 & 0.66 \\
\hline & Mujeres & 1.3 & 1 & 1 & 1 & 3 & 0.52 \\
\hline
\end{tabular}

Fuente: Elaboración propia.

Tabla 4

Lugar de origen de los migrantes centroamericanos entrevistados

\begin{tabular}{|c|c|c|c|c|c|c|c|c|c|c|}
\hline & \multicolumn{2}{|c|}{ Guatemala } & \multicolumn{2}{|c|}{ El Salvador } & \multicolumn{2}{|c|}{ Honduras } & \multicolumn{2}{|c|}{ Nicaragua } & \multicolumn{2}{|c|}{ Total } \\
\hline & $\mathrm{n}$ & $\%$ & $\mathrm{n}$ & $\%$ & $\mathrm{n}$ & $\%$ & $\mathrm{n}$ & $\%$ & $\mathrm{n}$ & $\%$ \\
\hline Varones & 25 & 78.1 & 2 & 6.2 & 4 & 12.5 & 1 & 3.1 & 32 & 53.3 \\
\hline Mujeres & 25 & 89.3 & 3 & 10.7 & & & & & 28 & 46.7 \\
\hline Total & 50 & 83.3 & 5 & 8.3 & 4 & 6.7 & 1 & 1.7 & 60 & 100 \\
\hline
\end{tabular}

Fuente: Elaboración propia. 


\section{Tabla 5}

\section{Características de los proxenetas entrevistados}

\begin{tabular}{|c|c|c|c|c|c|c|c|}
\hline & & Media & Mediana & Moda & Mín. & Máx. & $\begin{array}{l}\text { Desviación } \\
\text { estándar }\end{array}$ \\
\hline \multirow[t]{2}{*}{ Edad } & Varones & 42.2 & 42 & -- & 35 & 50 & 5.72 \\
\hline & Mujeres & 38.3 & 40 & 45 & 30 & 47 & 5.66 \\
\hline \multirow{2}{*}{$\begin{array}{l}\text { Años de } \\
\text { educación }\end{array}$} & Varones & 7.6 & 9 & 9 & 3 & 11 & 3.13 \\
\hline & Mujeres & 6.2 & 6 & 6 & 0 & 9 & 2.65 \\
\hline \multirow{2}{*}{$\begin{array}{l}\text { Edad cuando } \\
\text { comenzó a } \\
\text { trabajar }\end{array}$} & Varones & 10.6 & 10 & -- & 6 & 17 & 4.51 \\
\hline & Mujeres & 12.7 & 11 & 9 & 7 & 26 & 5.70 \\
\hline \multirow{2}{*}{$\begin{array}{l}\text { Edad cuando } \\
\text { empezó a } \\
\text { trabajar como } \\
\text { proxeneta }\end{array}$} & Varones & 30.4 & 28 & -- & 20 & 45 & 9.40 \\
\hline & Mujeres & 29.7 & 28 & 27 & 25 & 40 & 4.03 \\
\hline \multirow{2}{*}{$\begin{array}{l}\text { Años de } \\
\text { experiencia } \\
\text { como } \\
\text { proxenetas }\end{array}$} & Varones & 11.8 & 13 & -- & 5 & 15 & 3.96 \\
\hline & Mujeres & 8.7 & 7 & 10 & 3 & 20 & 4.37 \\
\hline
\end{tabular}

Fuente: Elaboración propia.

Tabla 6

Formas de violencia sufridas en el último viaje por los migrantes centroamericanos entrevistados

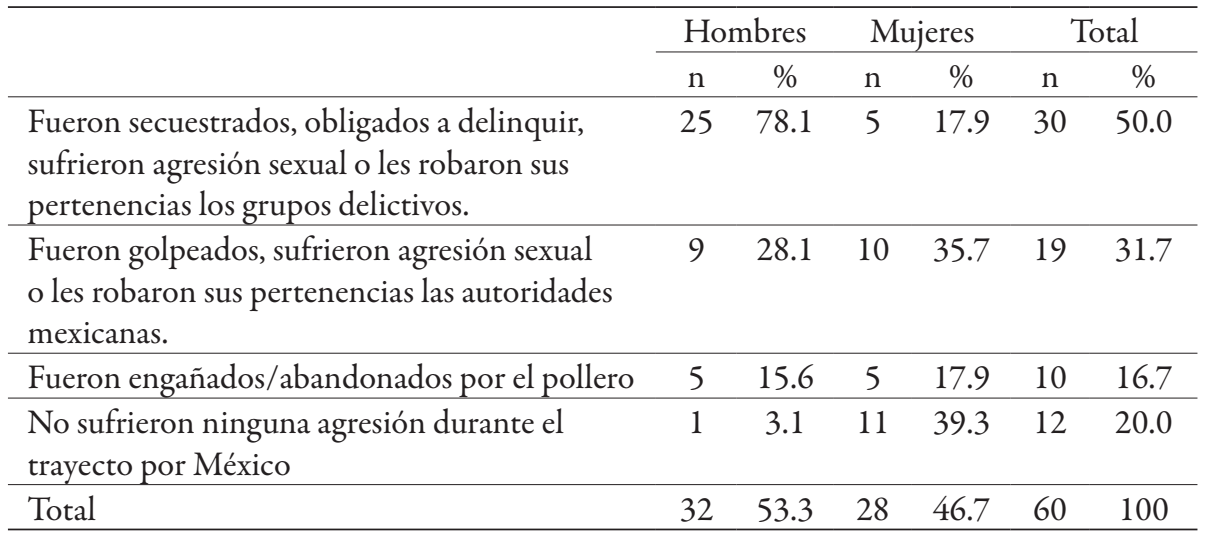

Fuente: Elaboración propia. 


\section{Tabla 7}

Formas de reclutamiento utilizadas por las redes dedicadas al tráfico sexual

\begin{tabular}{lcc}
\hline & $\mathrm{n}$ & $\%$ \\
\hline Manifestó que en ocasiones engañaba a las mujeres & 1 & 6.7 \\
\hline Señaló que siempre explicaba a las mujeres que trabajarían en la prostitución & 14 & 93.3 \\
\hline Total & 15 & 100 \\
\hline
\end{tabular}

Fuente: Elaboración propia.

\section{Tabla 8}

Modo de introducción de las migrantes centroamericanas en la industria de la prostitución

\begin{tabular}{|c|c|c|c|}
\hline & & $\mathrm{n}$ & $\%$ \\
\hline \multirow[t]{2}{*}{$\begin{array}{l}\text { Primer } \\
\text { viaje }\end{array}$} & $\begin{array}{l}\text { Manifestó que abandonó su país engañada (desconocía } \\
\text { que tendría que trabajar como prostituta) o la forzaron a } \\
\text { prostituirse. }\end{array}$ & 7 & 25.0 \\
\hline & $\begin{array}{l}\text { Señaló que nunca la engañaron; siempre trabajó } \\
\text { voluntariamente en la prostitución. }\end{array}$ & 21 & 75.0 \\
\hline \multirow[t]{3}{*}{$\begin{array}{l}\text { Último } \\
\text { viaje }\end{array}$} & $\begin{array}{l}\text { Manifestó que deseaba trabajar en la prostitución en Estados } \\
\text { Unidos (estaba reuniendo dinero para pagar la tarifa } \\
\text { cobrada por los polleros dedicados al tráfico sexual). }\end{array}$ & 22 & 78.6 \\
\hline & $\begin{array}{l}\text { Dijo que no le importaría trabajar en la prostitución en } \\
\text { Estados Unidos. }\end{array}$ & 5 & 17.8 \\
\hline & $\begin{array}{l}\text { Afirmó que no quería trabajar en la prostitución en Estados } \\
\text { Unidos. }\end{array}$ & 1 & 3.6 \\
\hline Total & & 28 & 100.0 \\
\hline
\end{tabular}

Fuente: Elaboración propia. 
Convergencia Revista de Ciencias Sociales, núm. 74, 2017, Universidad Autónoma del Estado de México

\section{Entrevistas citadas en el texto}

\begin{tabular}{|c|c|}
\hline Álvaro & Pollero de Nuevo León de 40 años de edad entrevistado en septiembre de 2011 \\
\hline Amadeo & Pollero de Nuevo León de 28 años de edad entrevistado en septiembre de 2011 \\
\hline Bartolomé & Pollero de San Luis Potosí de 30 años de edad entrevistado en octubre de 2011 \\
\hline Benito & Pollero de Tamaulipas de 30 años de edad entrevistado en diciembre de 2011 \\
\hline Benjamín & Pollero de Tamaulipas de 29 años de edad entrevistado en diciembre de 2011 \\
\hline Bonifacio & Pollero de San Luis Potosí de 45 años de edad entrevistado en diciembre de 2011 \\
\hline Carmen & Pollera de Tamaulipas de 38 años de edad entrevistada en diciembre de 2011 \\
\hline Cosme & Pollero de Nuevo León de 25 años de edad entrevistado en enero de 2012 \\
\hline Emilio & Pollero de Tamaulipas de 48 años de edad entrevistado en febrero de 2012 \\
\hline Enrique & Pollero de Tamaulipas de 35 años de edad entrevistado en febrero de 2012 \\
\hline Esteban & Pollero de Nuevo León de 35 años de edad entrevistado en abril de 2012 \\
\hline Felipe & Pollero de Tamaulipas de 40 años de edad entrevistado en abril de 2012 \\
\hline Francisco & Pollero de Tamaulipas de 45 años de edad entrevistado en abril de 2012 \\
\hline Gerardo & Pollero de Tamaulipas de 41 años de edad entrevistado en abril de 2012 \\
\hline Gregorio & Pollero de Tamaulipas de 38 años de edad entrevistado en mayo de 2012 \\
\hline Guillermo & Pollero de Tamaulipas de 36 años de edad entrevistado en junio de 2012 \\
\hline Horacio & Pollero de Tamaulipas de 30 años de edad entrevistado en junio de 2012 \\
\hline Humberto & Pollero de Tamaulipas de 40 años de edad entrevistado en junio de 2012 \\
\hline Ignacio & Pollero de Tamaulipas de 43 años de edad entrevistado en junio de 2012 \\
\hline Iván & Pollero de México D.F. de 39 años de edad entrevistado en julio de 2012 \\
\hline Jaime & Pollero de Tamaulipas de 35 años de edad entrevistado en julio de 2012 \\
\hline Jorge & Pollero de Tamaulipas de 40 años de edad entrevistado en julio de 2012 \\
\hline Juan & Pollero de Guanajuato de 34 años de edad entrevistado en julio de 2012 \\
\hline Leandro & Pollero de Tamaulipas de 45 años de edad entrevistado en julio de 2012 \\
\hline Manuel & Pollero de México D.F. de 35 años de edad entrevistado en septiembre de 2012 \\
\hline Marcelo & Pollero de Puebla de 32 años de edad entrevistado en septiembre de 2012 \\
\hline Marcos & Pollero de México D.F. de 40 años de edad entrevistado en septiembre de 2012 \\
\hline Martín & Pollero de San Luis Potosí de 38 años de edad entrevistado en noviembre de 2012 \\
\hline Miguel & Pollero de San Luis Potosí de 36 años de edad entrevistado en noviembre de 2012 \\
\hline Narciso & Pollero de Tamaulipas de 42 años de edad entrevistado en noviembre de 2012 \\
\hline Natalio & Pollero de Veracruz de 32 años de edad entrevistado en noviembre de 2012 \\
\hline Octavio & Pollero de Puebla de 35 años de edad entrevistado en noviembre de 2012 \\
\hline Olga & Pollera de México D.F. de 35 años de edad entrevistada en marzo de 2013 \\
\hline Oliverio & Pollero de Chiapas de 30 años de edad entrevistado en mayo de 2013 \\
\hline Omar & Migrante de Guatemala de 36 años de edad entrevistado en febrero de 2012 \\
\hline Paolo & Migrante de Guatemala de 24 años de edad entrevistado en agosto de 2012 \\
\hline Pascual & Migrante de Guatemala de 40 años de edad entrevistado en agosto de 2012 \\
\hline
\end{tabular}




\begin{tabular}{|c|c|}
\hline Patricio & Migrante de Guatemala de 20 años de edad entrevistado en septiembre de 2012 \\
\hline Rafael & Migrante de Guatemala de 39 años de edad entrevistado en septiembre de 2012 \\
\hline Raimundo & Migrante de Guatemala de 30 años de edad entrevistado en septiembre de 2012 \\
\hline Ramón & Migrante de Guatemala de 33 años de edad entrevistado en septiembre de 2012 \\
\hline Raúl & Migrante de Guatemala de 28 años de edad entrevistado en septiembre de 2012 \\
\hline Ricardo & Migrante de El Salvador de 28 años de edad entrevistado en septiembre de 2012 \\
\hline Roberto & Migrante de Guatemala de 30 años de edad entrevistado en septiembre de 2012 \\
\hline Rodolfo & Migrante de Guatemala de 32 años de edad entrevistado en septiembre de 2012 \\
\hline Rodrigo & Migrante de Honduras de 33 años de edad entrevistado en junio de 2012 \\
\hline Rubio & Migrante de Guatemala de 28 años de edad entrevistado en diciembre de 2012 \\
\hline Rufino & Migrante de Guatemala de 35 años de edad entrevistado en enero de 2013 \\
\hline Rufo & Migrante de Guatemala de 33 años de edad entrevistado en enero de 2013 \\
\hline Sabrina & Migrante de Guatemala de 27 años de edad entrevistada en septiembre de 2012 \\
\hline Salma & Migrante de Guatemala de 28 años de edad entrevistada en septiembre de 2012 \\
\hline Samanta & Migrante de Guatemala de 38 años de edad entrevistada en septiembre de 2012 \\
\hline Sara & Migrante de Guatemala de 32 años de edad entrevistada en septiembre de 2012 \\
\hline Socorro & Migrante de Guatemala de 30 años de edad entrevistada en septiembre de 2012 \\
\hline Sofía & Migrante de Guatemala de 34 años de edad entrevistada en noviembre de 2012 \\
\hline Sonia & Migrante de El Salvador de 31 años de edad entrevistada en noviembre de 2012 \\
\hline Susana & Migrante de Guatemala de 28 años de edad entrevistada en enero de 2013 \\
\hline Talía & Migrante de Guatemala de 25 años de edad entrevistada en febrero de 2013 \\
\hline Tamara & Migrante de Guatemala de 30 años de edad entrevistada en mayo de 2013 \\
\hline Tania & Proxeneta de Chihuahua de 45 años de edad entrevistada en septiembre de 2012 \\
\hline Telma & Proxeneta de Tamaulipas de 40 años de edad entrevistada en septiembre de 2012 \\
\hline Teodora & Proxeneta de México D.F. de 40 años de edad entrevistada en septiembre de 2012 \\
\hline Teresa & Proxeneta de Nuevo León de 32 años de edad entrevistada en septiembre de 2012 \\
\hline Venancia & Proxeneta de San Luis Potosí de 35 años de edad entrevistada en noviembre de 2012 \\
\hline Vesta & Proxeneta de Tamaulipas de 34 años de edad entrevistada en diciembre de 2012 \\
\hline Vivencia & Proxeneta de Tamaulipas de 45 años de edad entrevistada en diciembre de 2012 \\
\hline Vicenta & Proxeneta de Tamaulipas de 33 años de edad entrevistada en enero de 2013 \\
\hline Viola & Proxeneta de Tamaulipas de 35 años de edad entrevistada en febrero de 2013 \\
\hline Yael & Proxeneta de México D.F. de 35 años de edad entrevistado en septiembre de 2012 \\
\hline Ysmael & Proxeneta de Tamaulipas de 39 años de edad entrevistado en noviembre de 2012 \\
\hline Zacarías & Proxeneta de Tamaulipas de 45 años de edad entrevistado en noviembre de 2012 \\
\hline
\end{tabular}


Simón Pedro Izcara-Palacios. Premio Extraordinario de Doctorado (1997/1998), por la Universidad Complutense de Madrid, profesor de Sociología en la Unidad Académica Multidisciplinaria de Ciencias, Educación y Humanidades (Universidad Autónoma de Tamaulipas, México) y miembro del Sistema Nacional de Investigadores (Nivel 3). Principales líneas de investigación: estudios rurales y migratorios. Publicaciones recientes: "Manual de investigación cualitativa”, México: Fontamara (2014); "El oficio de agente facilitador del cruce fronterizo", en Papeles de Población, vol. 20, núm. 82, México (2014); “Coyotaje and Drugs: Two Different Businesses", en Bulletin of Latin American Research, Inglaterra (2014).

Recepción: 24 de agosto de 2015.

Aprobación: 21 de septiembre de 2016. 